\title{
Changes in pulmonary artery size before and after total cavopulmonary connection
}

Department of Paediatric Cardiology, University Children's Hospital Erlangen, Erlangen, Germany G Buheitel M Hofbeck U Tenbrink G Leipold $\mathrm{H}$ Singer

Department of Cardiac Surgery, University Erlangen, Erlangen, Germany J von der Emde

Correspondence to: Dr Buheitel, Abteilung für Kinderkardiologie, Univ Kinderklinik, Loschgestr 15, D 91054 Erlangen, Germany.

Accepted for publication 22 July 1997

Gernot Buheitel, Michael Hofbeck, Ursula Tenbrink, Georg Leipold, Jürgen von der Emde, Helmut Singer

\begin{abstract}
Objective-To assess changes in size of the central pulmonary arteries following a total cavopulmonary connection (TCPC). Design-A retrospective analysis of the angiographic diameters of the central pulmonary arteries, expressed as $\mathrm{z}$ scores, in infancy before the TCPC and $3.5(0.9)$ years (mean (SD)) later. Analysis of the relation between the pulmonary arteriolar resistance and the $\mathrm{z}$ scores at follow up.

Setting-Tertiary referral centre.

Patients-32 patients who had TCPC from February 1990 to July 1993.

Results-The patients were divided into two groups $(n=16)$ depending on their preoperative flow ratio: group $I, Q p / Q s$ $\leqslant 1$; group II, $Q p / Q s>1$. At the initial study in infancy the mean $z$ scores in group I were $\mathbf{- 6 . 0}$ for the right pulmonary artery (RPA) and $\mathbf{- 9 . 6}$ for the left pulmonary artery (LPA); in group II the respective values were -2.7 and -3.0 . Before the TCPC the values increased to 0.5 (RPA) and -0.5 (LPA) in group $I$, and to 8.8 (RPA) and 8.2 (LPA) in group II. At follow up the $z$ scores decreased to -2.4 (RPA) and -4.9 (LPA) in group $I$, and to 2.2 (RPA) and -0.7 (LPA) in group II. The changes in pulmonary artery diameters were significant for both groups ( $p<0.02)$. Following the TCPC, no significant difference in pulmonary arteriolar resistance index was found between patients with relatively small pulmonary arteries ( $z$ score RPA+LPA $\leqslant 0$ ) and those with relatively large pulmonary arteries $(z$ score RPA+LPA > 0).

Conclusions-Creation of a TCPC results in a significant reduction in size of the central pulmonary arteries. At a mean interval of 3.5 years following the TCPC, however, there was no significant difference in pulmonary arteriolar resistance index between patients with smaller and larger central pulmonary arteries.

(Heart 1997;78:488-492)
\end{abstract}

Keywords: total cavopulmonary connection; congenital heart disease; pulmonary artery size; pulmonary arteriolar resistance

During recent years, total cavopulmonary connection (TCPC) has found wide acceptance for separating the circulation in patients with univentricular hearts. ${ }^{1}$ To avoid negative sequelae of volume overload, cyanosis, or hypertrophy this procedure is now often performed in children less than four years of age..$^{2-6}$ The total cavopulmonary connection results in a nonpulsatile flow in the pulmonary arteries. ${ }^{178}$ Little is known, however, about the effects of this non-pulsatile flow on the subsequent growth of the pulmonary arteries. The purpose of our study was to determine the postoperative size of the central pulmonary arteries and to examine pulmonary arterial growth following the TCPC.

\section{Methods}

Between February 1990 and July 1996, a TCPC was performed on 56 patients at our unit. Thirty two of these patients, who underwent elective cardiac catheterisation 3.5 (0.9) years (mean (SD)) after the TCPC, formed our study cohort (table 1). The mean age at TCPC was 5.8 (4.0) years.

The pulmonary artery diameters were measured at the following times: (1) at the initial cardiac catheterisation, which was performed-except in one patient-within the first year of life, (2) before the TCPC, and (3) during the elective postoperative cardiac catheterisation. Angiographs allowing exact measurements of the central pulmonary arteries were available from 27 patients in the first year of life and from all patients before and after the TCPC. The maximum diameters of the pulmonary arteries were determined in anteroposterior projection just proximal to the origin of the first upper lobe branch. In five patients we could not obtain this information from the angiographs done during the first year of life, either because the study had been performed in another unit (two patients) or because opacification of the central pulmonary arteries was not clear enough to allow an exact measurement (three patients). Following the TCPC none of our patients had a clinically relevant obstruction of the total cavopulmonary connection or of the central pulmonary arteries.

Based on these measurements we calculated the $\mathrm{z}$ score values of the pulmonary artery diameters - that is, the difference between the size of the pulmonary arteries of the patients and the pulmonary artery size in normal subjects, expressed in standard deviations and corrected for body surface area. For normal values and standard deviations we used the data published by Rammos et al. ${ }^{9}$ 
Table 1 Patients and diagnoses

\begin{tabular}{|c|c|c|c|c|c|c|c|c|c|c|}
\hline & $\begin{array}{l}\text { Number of } \\
\text { patients }\end{array}$ & $T A$ & $D I L V$ & DORV & $\begin{array}{l}\text { Complex } \\
\text { TGA or } \\
A V S D\end{array}$ & $\begin{array}{l}\text { Mean age at first } \\
\text { cardiac cath (years) }\end{array}$ & $\begin{array}{l}\text { Mean age at } \\
\text { TCPC (years) }\end{array}$ & $\begin{array}{l}\text { Mean age at } \\
\text { follow up study } \\
\text { (years) }\end{array}$ & $\begin{array}{l}\text { Mean weight at } \\
\text { follow up study } \\
\text { (kg) }\end{array}$ & $\begin{array}{l}\text { Mean interval of } \\
\text { follow up (years) }\end{array}$ \\
\hline Group I & 16 & 8 & 5 & 2 & 1 & $0.12(0.22)$ & $3.46(2.38)$ & $6.97(2.55)$ & $21.3(6.1)$ & $3.51(0.76)$ \\
\hline Group II & 16 & 2 & 4 & 3 & 7 & $0.79(2.34)$ & $8.14(3.95)$ & $11.63(4.01)$ & $36.2(10.1)$ & $3.49(1.01)$ \\
\hline Total & 32 & 10 & 9 & 5 & 8 & $0.45(1.66)$ & $5.80(3.99)$ & $9.30(4.07)$ & $28.7(11.2)$ & $3.50(0.88)$ \\
\hline
\end{tabular}

Values are numbers of patients or mean (SD).

AVSD, atrioventricular septal defect; DILV, double inlet left ventricle; DORV, double outlet right ventricle; TA, tricuspid atresia; TGA, transposition of the great arteries.

The flow ratios and the pulmonary arteriolar resistance (indexed) were calculated before and after the operation using Fick's principle. Since there were considerable differences in the pulmonary blood flow ratios of our patients submitted for TCPC, we divided them into two groups. Group I consisted of 16 patients with a preoperative flow ratio $(\mathrm{Qp} / \mathrm{Qs}) \leqslant 1$, while in group II the preoperative flow ratio was $>1$ (table 1). Two of the five patients in whom angiographic measurements were unavailable from the first study in infancy belonged to group I; the remaining three patients belonged to group II.

Statistical analysis was performed using the Wilcoxon signed rank test and the Freedman test for dependent variables. The MannWhitney $U$ test was used for independent variables. $\mathrm{P}$ values of $<0.05$ were considered significant.

\section{Results}

Among the patients with a preoperative Qp/Qs ratio $\leqslant$ I (group I) both the right and the left pulmonary artery were rather small at the time of the initial study (fig 1). The mean $\mathrm{z}$ scores of both pulmonary arteries were well below the normal limits, with the left pulmonary artery being smaller than the right (mean $\mathrm{z}$ score of the right pulmonary artery -6.0 , mean $z$ score of the left pulmonary artery -9.6). Most of these patients underwent shunt procedures during the neonatal period or in the first year of life. Before the TCPC we found a significant increase in the $\mathrm{z}$ scores of both pulmonary arteries (fig 1). At that time the mean value of both pulmonary arteries was in the normal range (right 0.5 , left $-0.5)$. At the follow up study 3.5 years after the total cavopulmonary connection we found a reduction in the mean $\mathrm{z}$ scores of both pulmonary arteries (right -2.4 , left -4.9 , fig 1 ). These changes of the pulmonary artery diameters between the three examinations (initial study, pre-TCPC, post-TCPC) were significant $(p<0.02)$. Although there was an increase in the $\mathrm{z}$ scores of both pulmonary arteries between the initial study and the follow up study 3.5 years after TCPC $(p<0.05)$, in comparison with the normal population the eventual size of the pulmonary arteries in the patients of group I remained too small.

In the patients with a $\mathrm{Qp} / \mathrm{Qs}$ ratio > 1 before the total cavopulmonary connection we again found that both pulmonary arteries had subnormal diameters at the time of the initial study. The mean $\mathrm{z}$ scores of the right and left pulmonary artery were -2.7 and -3.0 , respectively (fig 2). Before the TCPC we noted a
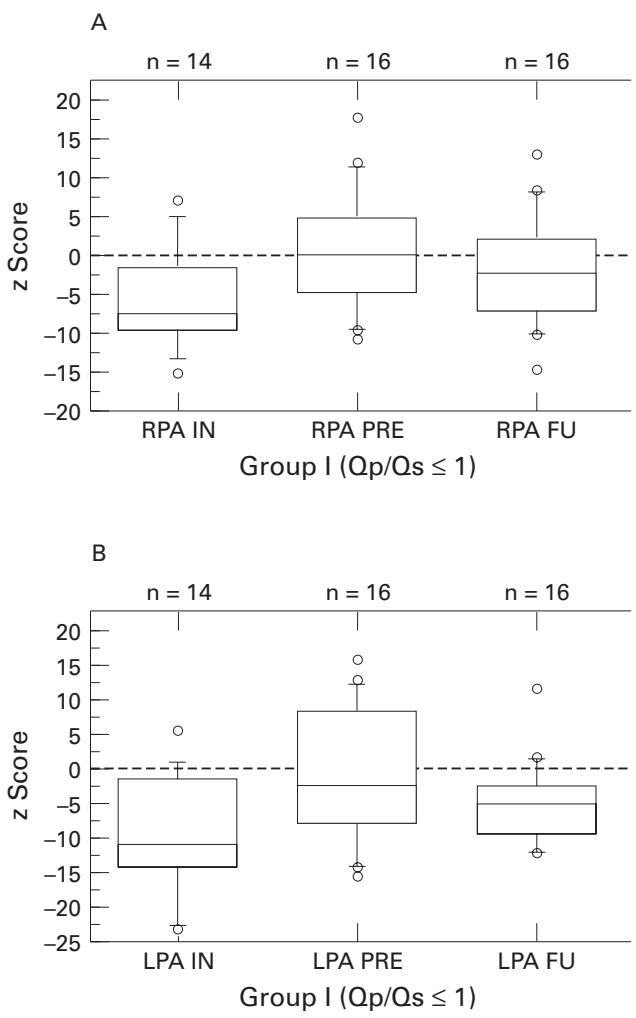

Figure 1 Diameters (given as z scores) of the central right (RPA) and central left pulmonary artery (LPA) at the initial cardiac catheterisation (IN), before total cavopulmonary connection (TCPC) (PRE), and at the follow up study 3.5 years after TCPC (FU) in patients of group I. For both pulmonary arteries the changes in the diameters between the three points were significant $(p<0.02)$, and the difference between IN and FU was also significant $(p<0.05)$.

considerable increase in pulmonary artery size, bringing the diameters of both pulmonary arteries into the supranormal range (mean $\mathrm{z}$ scores: right pulmonary artery 8.8 , left pulmonary artery 8.2 , fig 2 ). At the follow up study we found again a relative decrease in the $z$ scores of the central pulmonary arteries. Following the modified Fontan procedure the mean $\mathrm{z}$ score of the right pulmonary artery had decreased to 2.2 and of the left pulmonary artery to -0.7 (fig 2). Again these changes in diameter between the three examinations (initial study, pre-TCPC, post-TCPC) proved to be significant $(p<0.02)$. However, in group II there was a significant increase in $\mathrm{z}$ score only for the right pulmonary artery between the initial study and the follow up study 3.5 years after TCPC $(p<0.03)$; the value for the left pulmonary artery remained unchanged during this period. Nevertheless the size of the pulmo- 
A
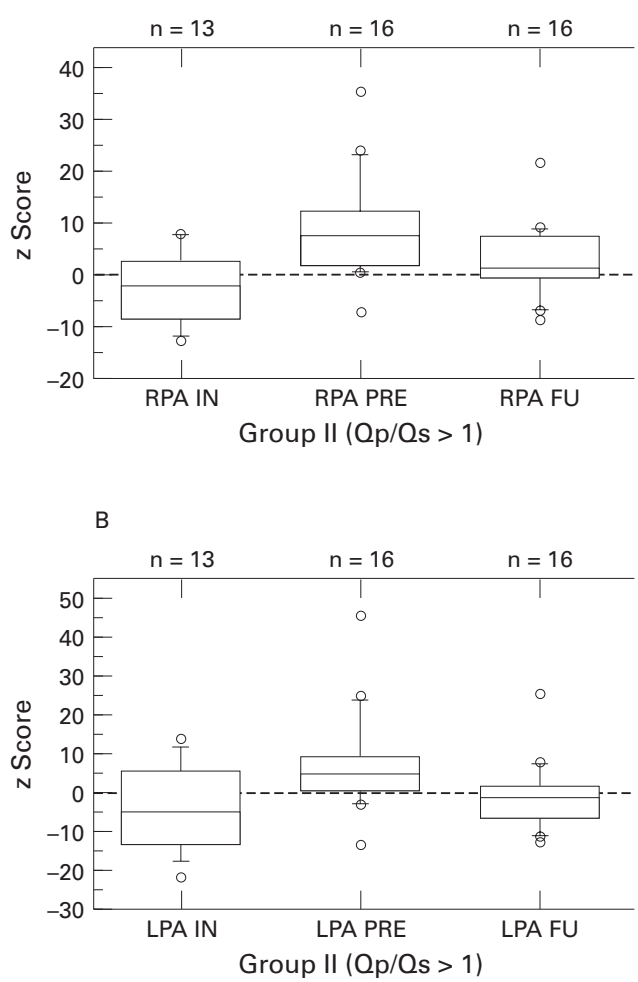

Figure 2 Diameters (given as $z$ scores) of the central right (RPA) and central left pulmonary artery (LPA) at the initial cardiac catheterisation (IN), before total cavopulmonary connection (TCPC) (PRE), and at the follow up study 3.5 years after TCPC (FU) in patients of group II. For both pulmonary arteries the changes in the diameters between the three points were significant $(p<0.02)$; the difference between IN and FU was significant only for the right pulmonary artery $(p<0.03)$

nary arteries following the TCPC in these patients was similar to the expected value for a normal population, with the right pulmonary artery being larger than the left. Exclusion of the five patients in whom angiographic data were not available from infancy produced no changes in the significance levels.

The postoperative pulmonary arteriolar resistance index did not differ significantly in the two groups from the preoperative values. In order to determine whether there was a correlation between postoperative pulmonary arteri-

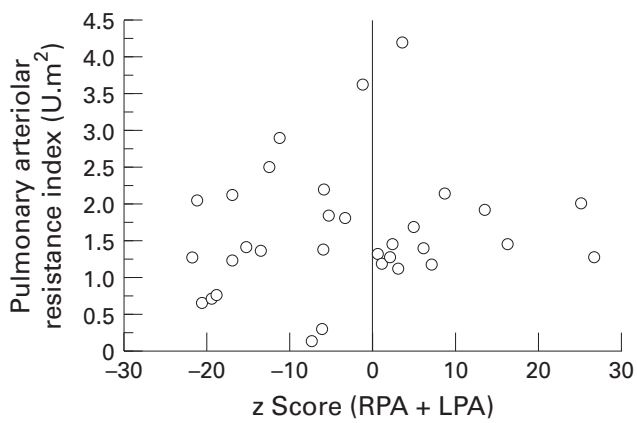

Figure 3 Diagram showing the pulmonary arteriolar resistance index (PARI) at the time of follow up in relation to pulmonary artery (PA) diameters (expressed as z score right $P A+z$ score left $P A)$. There was no significant

difference between patients with larger pulmonary arteries $(z$ score right $P A+z$ score left $P A>0)$ and smaller

pulmonary arteries ( $z$ score right $P A+z$ score left $P A<0$ ). olar resistance and the postoperative size of the central pulmonary arteries, we compared the children with rather small pulmonary arteries (sum of the postoperative $\mathrm{z}$ scores of both pulmonary arteries $\leqslant 0$ ) with the children who had larger pulmonary arteries (sum of $\mathrm{z}$ scores $>0$ ). We found no significant difference in the pulmonary arteriolar resistance index between the two groups (fig 3). Among our 32 patients, however, there were three children who had developed a rather high pulmonary vascular resistance at follow up $\left(3.6,4.1\right.$, and $\left.2.9 \mathrm{U}_{\mathrm{U}} \mathrm{m}^{2}\right)$. None of these three patients had a raised pulmonary vascular resistance before the total cavopulmonary connection. Two of the three belonged to group II $(\mathrm{Qp} / \mathrm{Qs}>1)$, with rather large pulmonary arteries before the TCPC. The age at TCPC was 3, 10, and 15 years. At follow up, one had large pulmonary arteries, one had quite normal sized arteries, and one had small arteries. The postoperative decrease in the $\mathrm{z}$ score of the central pulmonary arteries was comparable to the rest of the patients in each group.

\section{Discussion}

Since there is no pumping chamber supporting the pulmonary circulation, a total cavopulmonary connection results in an almost nonpulsatile flow in the central pulmonary arteries. ${ }^{178}$ Until now there have been few reports examining the effect of this nonpulsatile flow on the subsequent growth of the central pulmonary arteries and on the pulmonary arteriolar resistance. We are aware of three recent studies of pulmonary arterial growth following bidirectional Glenn procedures or Fontan operations. Mendelsohn et al and Penny et al reported a reduction in size of the central pulmonary arteries at mean intervals of 17.6 and 14 months after a bidirectional Glenn procedure. $^{1011}$ Their patients, however, were different from our cohort, since, following a bidirectional Glenn procedure, only the systemic venous return of the superior vena cava passes through the pulmonary vascular bed. Lundstrom et al examined 15 patients after a Fontan procedure. ${ }^{12}$ Postoperatively the pulmonary arteries were comparable to the preoperative size in 10 patients, while in the remaining five they had failed to grow because of the development of severe conduit obstruction. Because none of our patients had an obstruction of the total cavopulmonary anastomosis or of the central pulmonary arteries, we were able to assess the pulmonary artery size following a modified Fontan procedure without the detrimental effects of an anatomical obstruction.

In order to examine the influence of pulmonary blood flow before the total cavopulmonary connection on the pulmonary artery size, we divided our patients into two groups, based on the preoperative flow ratio, Qp/Qs. Group I included the patients with decreased pulmonary blood flow, and group II the patients with increased pulmonary blood flow. Both groups showed a considerable increase in size of the central pulmonary arteries between the initial catheterisation in the first year of life and the 
second study before the modified Fontan procedure. The patients in group I, however, with decreased pulmonary blood flow, had smaller central pulmonary arteries than the patients in group II. Following the total cavopulmonary connection we noted a decrease in the $\mathrm{z}$ scores of the central pulmonary arteries in both groups. Since the patients with increased pulmonary blood flow preoperatively had larger than normal central pulmonary arteries, the eventual size of the arteries following the postoperative decrease was similar to that expected in a normal population. In the children with decreased pulmonary blood flow before the total cavopulmonary connection, however, the postoperative decrease in size resulted in subnormal diameters of both central pulmonary arteries. The fact that data on pulmonary size in infancy were missing in five of our patients did not influence the results, since following exclusion of those patients we found identical significance levels in the remaining cohort. The relative decrease in size of the central pulmonary arteries seems to be independent of the postoperative pulmonary blood flow, since patients in group I had a considerable increase in the $\mathrm{Qp} / \mathrm{Q}$ s ratio (from $0.74: 1$ to $0.92: 1$ ) following the modified Fontan procedure. Furthermore the changes in pulmonary artery size after the total cavopulmonary connection did not result in an increase in postoperative pulmonary arteriolar resistance. In our cohort we found no significant difference between patients with subnormal pulmonary artery diameters and those with supranormal diameters.

In our opinion the early postoperative reduction in central pulmonary artery size is not only attributable to the creation of non-pulsatile flow in the central pulmonary arteries. Before the modified Fontan procedure all our patients had an abnormally turbulent flow in the central pulmonary arteries, resulting either from native pulmonary valvar or subvalvar stenoses, from palliative banding procedures, or from aortopulmonary shunts. The relative decrease in size of the central pulmonary arteries within our follow up period of 3.5 years might also be the result of abolishing the turbulent flow in the central pulmonary arteries.

Further studies will be required to determine the growth of the central pulmonary arteries in the long term follow up after a total cavopulmonary connection. This applies specifically for those children with reduced pulmonary blood flow before the modified Fontan procedure, since these children developed subnormal sized central pulmonary arteries in the medium term follow up. In our cohort the patients with a preoperatively reduced pulmonary blood flow underwent the TCPC at a younger age (mean 3.46 years) than the patients with an increased pulmonary blood flow (mean 8.14 years), who were less cyanotic. At present we do not think it justifiable to conclude that the younger age of these patients is responsible for the inadequate growth of their central pulmonary arteries. Since the pulmonary arteries in these children were smaller than normal preoperatively, the abolition of turbulent flow could well explain their subnormal size following the modified Fontan procedure.

If non-pulsatile flow has a negative influence on the subsequent growth of the central pulmonary arteries, one would expect a lack of growth of these vessels on long term follow up. There is some evidence that pulsatile flow in the central pulmonary arteries has a positive influence on pulmonary artery size following a bidirectional Glenn procedure. At a mean interval of 16.6 months after a bidirectional cavopulmonary anastomosis, Kobayashi et al found no significant difference in size of the central pulmonary arteries in 10 patients who had a pulsatile pulmonary blood flow provided by an additional modified Blalock-Taussig shunt or by a residual communication of the central pulmonary arteries with the systemic ventricle. ${ }^{13}$ Inadequate growth of the central pulmonary arteries in younger patients would have a major influence on the assessment of the ideal age for a TCPC. The results of this study did not change our present policy of performing the TCPC electively in the third or fourth year of life. This policy seems to be justified by several studies that report better mid-term results in relation to the function of the systemic ventricle and the incidence of postoperative arrhythmias in patients who are operated on at a younger age. ${ }^{14-16}$ Since bidirectional Glenn procedures or TCPC are now often performed in infancy and in early childhood, ${ }^{17}$ it is mandatory to obtain more information about the long term growth of the central pulmonary arteries. We therefore plan to repeat our study in an interval of three to five years.

1 De Leval MR, Kilner P, Gewillig M, Bull C. Total cavopulmonary connection. A logical alternative to atriopulmonary connection for complex Fontan operations. 7 Thorac Cardiovasc Surg 1988;96:682-95.

2 Hofbeck M, Singer H, Scharf J, Rupprecht T, Ries M, Buheitel G, et al. Die totale kavopulmonale Anastomose: Risikofaktoren und Ergebnisse bei Patienten unter 4 Jahren. Z Kardiol 1994;83:615-22.

3 Kaulitz R, Ziemer G, Luhmer I, Paul T, Kallfelz HC. Total cavopulmonary anastomosis in patients less than three years of age. Ann Thorac Surg 1995;60:563-7.

4 McGary SA, Myers JL, Waldhausen JA. The modified FonMcGary SA, Myers JL, Waldhausen JA. The modified Fon-
tan operation in patients less than 4 years of age [abstract]. Circulation 1994;90: I-254.

5 Pearl JM, Laks H, Drinkwater DC, Capouya ER, George BL, Williams RG. Modified Fontan procedure in patients less than 4 years of age. Circulation 1992;86(suppl 2):II-100-105.

6 Weber HS, Gleason MM, Myers JL, Waldhausen JA, Cyran SE, Baylen BG. The Fontan operation in infants less than 2 years of age. 7 Am Coll Cardiol 1992;19:828-33.

7 Hatle L. Non-invasive assessment of the Fontan circulation. In: Hess J, Sutherland GR, eds. Congenital heart disease in adolescents and adults. Berlin: Kluwer Academic Publishers, 1992:125-32.

8 Redington AN, Penny D, Shinebourne EA. Pulmonary blood flow after total cavopulmonary shunt. Br Heart $\mathcal{F}$ 1991;65:213-17.

9 Rammos S, Kramer HH, Trampisch HJ, Krogmann ON, Kozlik R, Bourgeois M. Normalwerte des Wachstums der Pulmonalarterien im Kindesalter. Herz 1989;14:348-57.

10 Mendelsohn AM, Bove EL, Lupinetti FM, Crowley DC, Lloyd TR, Beekman RH. Central pulmonary artery growth patterns after the bidirectional Glenn procedure. $\mathcal{F}$ Thorac Cardiovasc Surg 1994;107:1284-90.

11 Penny DJ, Pawade A, Wilkinson JL, Karl TR. Pulmonary artery size after bidirectional cavopulmonary connexion [abstract]. Circulation 1994;90:I-98.

12 Lundstrom U, Nisula L, Pesonen E, Sairanen H, Louhimo I, Wallgren EI. Pulmonary artery growth failure after Fontan operation - cause and consequence [abstract]. Cardiol tan operation - cause and con

13 Kobayashi J, Matsuda H, Nakano S, Shimazaki Y, Ikawa S, Mitsuno M, et al. Hemodynamic effects of bidirectional cavopulmonary shunt with pulsatile pulmonary flow. Circucavopulmonary shunt with pulsatile pulm
lation 1991;84(suppl 3): III-219-25. 
14 Uemura H, Yagihara T, Kawashima Y, Yamamoto F, Nishigaki $\mathrm{K}$, Matsuki $\mathrm{O}$, et al. What factors affect ventricular gaki $\mathrm{K}$, Matsuki $\mathrm{O}$, et al. What factors affect ventricular
performance after a Fontan-type operation. $\mathcal{F}$ Thorac performance after a Fontan-typ

15 Cecchin F, Johnsrude CL, Perry JC, Friedman RA. Effect of age and surgical technique on symptomatic arrhythmias after the Fontan procedure. Am f Cardiol 1995;76:386-91.
16 Gewillig M, Wyse RK, de Leval MR, Deanfield JE. Early and late arrhythmias after the Fontan operation: predisposing factors and clinical consequences. Br Heart f 1992;67:72-9. 17 Slavik Z, Lamb RK, Webber SA, Devlin AM, Keeton BR, Monro JL, et al. Bidirectional superior cavopulmonary anastomosis: how young is too young. Heart 1996;75:7882

\section{IMAGES IN CARDIOLOGY}

\section{Left atrial dissection after mitral valve reconstruction}
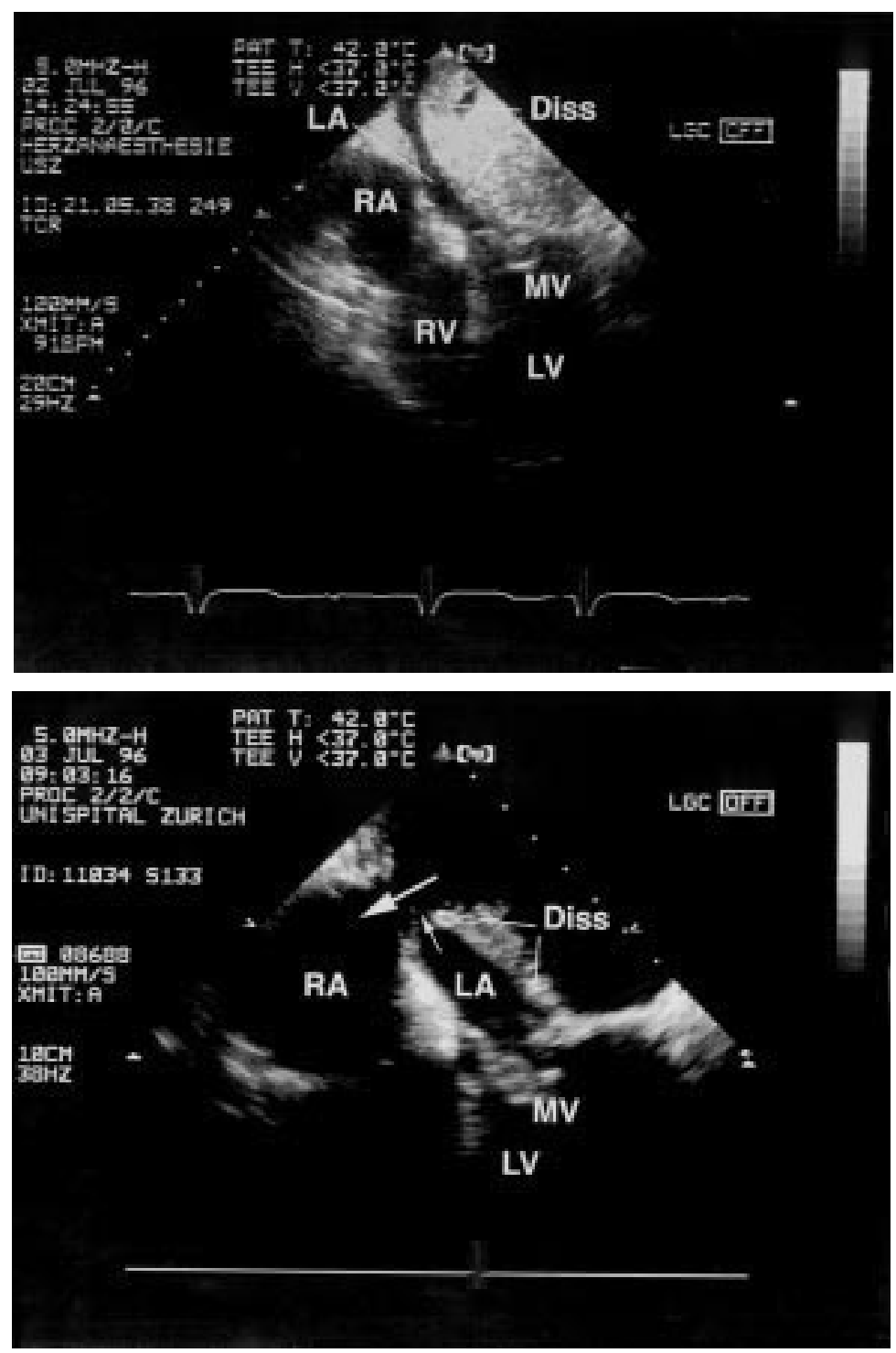

A 58 year old man underwent mitral valve repair for prolapse of the anterior valve leaflet and consecutive severe mitral regurgitation. After weaning from cardiopulmonary bypass, transoesophageal echocardiography showed a successfully reconstructed mitral valve, but a large mass within or behind the left atrium that had not been present before surgery. Hiatal hernia or haematoma formation from oesophageal perforation were excluded by gastroscopy using a paediatric gastroscope while the echocardiography probe was still in place. Suspicion of left atrial thrombus formation could neither be excluded nor confirmed by additional epicardial echocardiography, cardiopulmonary bypass was therefore restarted. Opening the left atrium revealed a bulging posterior left atrial wall and near obliteration of the atrial lumen due to dissection and haematoma formation within the dissected cavity. The entry into the false lumen could not be identified, and the false lumen was therefore marsupialised transseptally to the right atrium (large arrow); the small arrow indicates a residual shunt between the left atrium and the transseptal marsupialisation. Postoperative course was uneventful. Repeat control echocardiography over the following months showed persisting bidirectional perfusion of the false lumen from both the left and right atria, and persistence of a small residual shunt between the left atrium and the marsupialisation. (RA, right atrium; RV, right ventricle; LA, left atrium; LV, left ventricle; MV, mitral valve; Diss, dissected left atrial wall.)

EDITH R SCHMID DANIEL SCHMIDLIN ROLF JENNI 